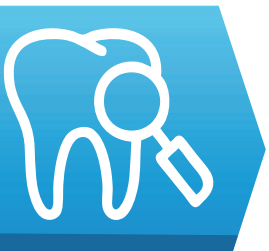

DENTAL MEDICINE

\title{
Current treatment modalities of orthodontically induced white spot lesions and their outcome - a literature review
}

*Lavinia Luminiţa Cosma ${ }^{1}$, *Raluca Diana Şuhani ${ }^{1}$, *Anca Mesaroş², *Mîndra Eugenia Badea ${ }^{3}$

1) Department of Pediatric Dentistry, Iuliu Haţieganu University of Medicine and Pharmacy, Cluj-Napoca, Romania

2) Department of Dental Propedeutics and Esthetics, Iuliu Haţieganu University of Medicine and Pharmacy, Cluj-Napoca, Romania

3) Department of Prevention in Dentistry, Iuliu Haţieganu University of Medicine and Pharmacy, Cluj-Napoca, Romania

* All authors have equal contributions

DOI: $10.15386 /$ cjmed-1090

Manuscript received: 20.06 .2018 Received in revised form: 17.09 .2018 Accepted: 24.09.2018

Address for correspondence: raluca.suhani@gmail.com

\begin{abstract}
Introduction. White spot lesion is a demineralization of the enamel that appears as a white spot on the surfaces of the tooth. The cause of this spot is determined by the activity of the bacterial plaque and it represents the initial stage of a carious lesion. This lesion is a common side effect for patients with fixed orthodontic appliances mainly because of the brackets' position that favors the accumulation of plaque that ultimately leads to the formation of the white spot.
\end{abstract}

Methods. We conducted a search on a single database, PubMed. "Orthodontic", "white spot lesions", "enamel demineralization treatment" and "remineralization" were the search terms used. We found 324 articles, but we took in consideration only the ones from the last 10 years, which resulted in 223 articles.

Results. The first step after research was article selection: first by scrutinizing the title and secondly by reviewing the abstracts or full texts. The exclusion criteria were: meta-analysis, reviews, original articles regarding prevention of white spot lesions and their prevalence or incidence. We included the articles that seemed relevant for the treatment of white spot lesions, made either on extracted teeth either on orthodontic patients. We found 75 articles to be eligible for this research and we eliminated 5 because of the lack of an abstract or full text and a further 22 were rejected because they did not fit the aforementioned criteria.

Conclusion. Although some traditional methods for the treatment of white spot lesions seem to have undesirable results, nowadays with new technologies and thorough investigations in nanotechnology, the eradication of the lesion appears to be short term.

Keywords: orthodontic, white spot lesion, enamel demineralization treatment, remineralization

\section{Introduction}

White spot lesion is a demineralization of the enamel that appears as a patch on the tooth surfaces [1]. Its cause is determined by bacterial plaque activity and it represents the initial stage of a carious lesion [2]. This lesion is a common side effect for patients with fixed orthodontic appliances mainly because of the bracket's position that favors plaque accumulation that ultimately leads to the formation of the white spot [3].

The most frequent surfaces, where the white spot lesion appears, were the buccal maxillary surface, around the bracket and in the gingival area, according to studies performed by Goerlick et al. [4]. Chapman et al. [3] concluded that white spot incidence for the maxillary teeth was higher for the lateral incisor (34\%), similar for canines $(31 \%)$ and premolars $(28 \%)$ and lower for the central incisors (17\%).
Orthodontic professionals still have to confront this problem, mainly because patients don't take into consideration particular brushing techniques required and also other auxiliary means. Although they frequently receive a full list of instructions, they tend to be neglectful and as a result white spot lesions occur [5].

Treatment of white spot lesions is being debated for a while. Today it still represents a controversial topic because of a desperate need of a cure.

The aim of this literature review is to identify and assess every treatment used in achieving white spot lesion remineralization, induced by fixed orthodontic appliances.

\section{Material and methods}

We conducted this search by using a single database: PubMed. "Orthodontic", "white spot lesions", "enamel 
demineralization treatment" and "remineralization" were the terms used in the search. We found 324 articles, we only considered the ones from the last 10 years, from 2007 onwards that gave us a total of 223 articles. The first step was the article selection: first by scrutinizing the title and secondly by reviewing the abstracts or full texts.

The exclusion criteria were: meta-analysis, reviews and original articles regarding prevention of white spot lesions and their prevalence or incidence.

We included papers that seemed relevant for the treatment of white spot lesions, made either on extracted teeth either on orthodontic patients. We found 75 articles to be eligible for this research and we eliminated 5 because of the lack of an abstract or full text. A further 22 were rejected because they did not fit the aforementioned criteria (Figure 1).

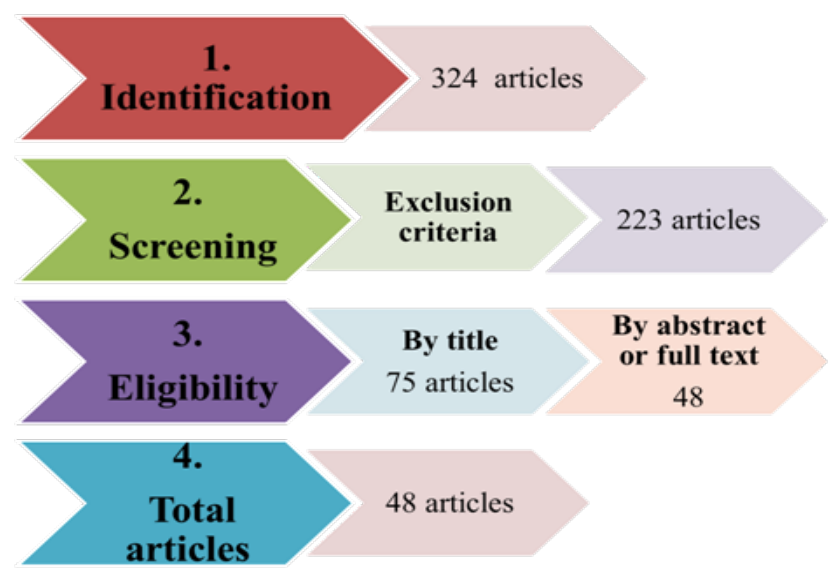

Figure 1. Article selection method.

\section{Results and discussion}

Numerous treatment methods were used, as represented in the figure below (Figure 2).

The most common preventive and remineralizing agent used was fluoride. The safety of fluoride has been proven with topical applications such as varnish, gels or mouthwash [6].

Stafford et al. [7] made a research in which he tested the application of fluoride varnish on orthodontic patients and tried to evaluate its effect on white spot lesions. He concluded that this treatment showed improvements by reducing the lesions' size during the first 6 months after orthodontic appliance removal. Du et al. [8] also studied the application of fluoride varnish $(5 \%$ sodium fluoride,

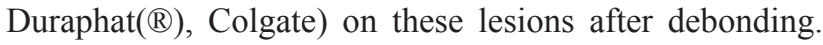
They came to the same conclusion - the varnish helps reduce white spot lesions after debonding and it should be used as a preventive treatment. On the other hand, Majithia et al. [9] compared the application of different varnishes on artificially induced enamel demineralization, such as $M I$ Varnish $^{\mathrm{TM}}$ (5\% sodium fluoride varnish with Recaldent ${ }^{\mathrm{TM}}$
(CPP-ACP) Technology, GC Corporation, Tokyo, Japan), Premier $^{\circledR}$ Enamel Pro ${ }^{\circledR}$ Varnish $(5 \%$ sodium fluoride varnish with ACP Formula, Premier Dental Products Co., Canada) and Flor-Opal ${ }^{\circledR}$ Varnish White (5\% sodium fluoride varnish, Ultradent Products, Inc., USA).

They observed that three commercial varnishes had some remineralization potential, but one of them was more potent regarding enamel microhardness (MI Varnish $\left.{ }^{\mathrm{TM}}\right)$. In a study performed by Restrepo et al. [10] fluoride varnish, chlorhexidin gel and daily home care were compared. Results showed that fluoride varnish slows down the progression of the lesion [10]. Another study, implemented by $\mathrm{He}$ et al. compared fluoride varnish with fluoride film for reconversion of white spot lesions [11]. He et al. [11] suggested that fluoride varnish had a slightly better effect while some patients experienced remineralization, certified by a decrease in size and a lack of fluorescence in the vicinity of the white spot lesion.

Fluoride tablets were also researched to test their impact on these lesions. In the article written by Bansal et al. [12] homeopathic tablets such as calcareafluoricain with a dosage of 4 tablets twice a day, were evaluated on artificially induced lesions. Utilizing SEM, some remineralization effects were documented with an increased microhardness value.

Some studies evaluated the effectiveness of fluoridated chewing sticks. Miswaks. Baeshen et al. [13] tested this approach and the effect of a specific chewing stick on the white spot lesions on orthodontic patients. They seem to have found some remineralizing potential [13].

Fluoridated milk was also tested. Sköld-Larsson et al. [14] concluded that daily use of fluoridated milk might remineralize white spot lesions [14].

Gokce et al. [15] evaluated the effects of toothpaste on white spot lesions by creating artificial lesions and treating them with fluoride toothpaste (Colgate Total ${ }^{\circledR}$ ), Novamin toothpaste (Sensodyne ${ }^{\circledR}$ Repair and Protect) and probiotic toothpaste (GD Probiotic Toothpaste ${ }^{\circledR}$ ) [15]. The Novamin toothpaste showed an increased fluorescence compared to the others [15]. Agarwal et al. [16] made an 8 week study, comparing fluoride toothpaste (Sodium Fluoride EP $0.32 \%$ w/w 1450 ppm F, Colgate Total 12, India) with non-fluoride toothpaste, on white spot lesions in post-orthodontic patients. They noticed a significant difference between these groups, as the one with the fluoride toothpaste presented a reduced clinical index [16]. Various other toothpastes were tested on demineralized teeth such as the study from Jo et al. [17], who compared fluoride toothpaste, casein phosphopeptide amorphous calcium phosphate complex (CPP-ACP) and functionalized $\beta$-tricalcium phosphate (fTCP) containing toothpaste [17]. They seem to have found that sodium fluoride toothpaste and CPP-ACP are more effective in reducing white spot lesions [17]. On the contrary, Ballard et al. [18] who studied three commercial toothpastes NovaMin (Dr. Collins Inc), 


\section{Types of treatment}

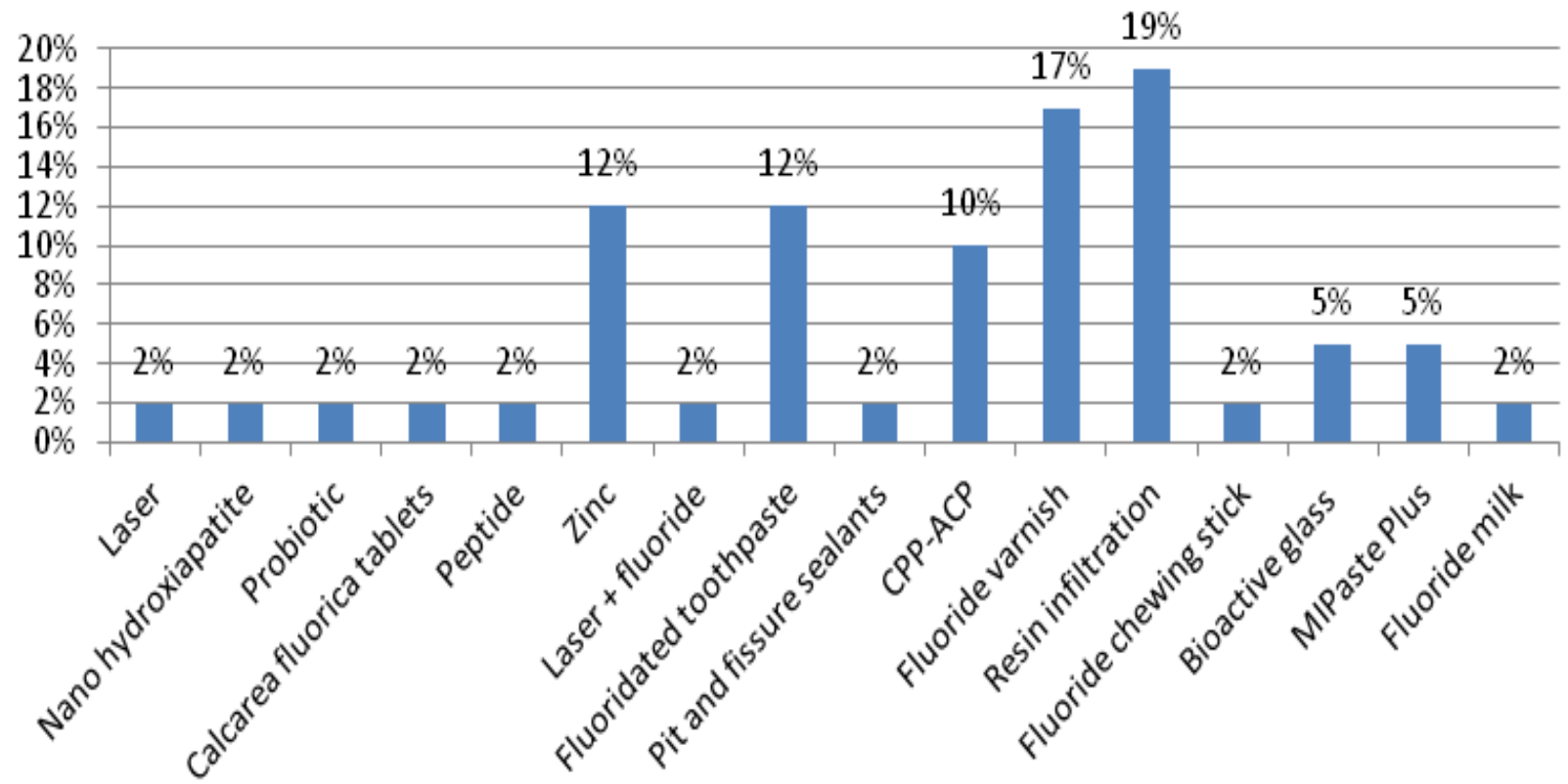

Figure 2. Percentage distribution of selected articles according to the treatment option utilized.

Prevident5000 (Colgate, New York, NY) and MIPastePlus (GC America, Alsip, Ill) found no significant difference between them regarding the lesions [18]. An interesting study made by Mensinkai et al. [19] on three fluoride toothpastes at different concentrations: 500 ppm F, 1100 ppm F and 500ppm F plus fTCP; showed that the 500 ppm F plus fTCP produced 10 to $38 \%$ better mineral recovery than the other two, while reducing the lesions' size by $30 \%$ and its depth by $52 \%$. 500ppm F with fTCP seemed to have comparable benefits with 1100 ppm F [19].

Fluoride toothpastes were improved over the years by adding specific agents. A controversial agent would be $\mathrm{Zn}$, as it has some demineralizing and also remineralizing properties. It can reduce enamel solubility, but it can also reduce crystal growth of brushite, octacalcium phosphate and hydroxyapatite $[20,21]$. After adding $\mathrm{Zn}$ to a fluoride toothpaste, some researchers such as Ten Cate et al. [22], observed a decrease in enamel demineralization and concluded this couldn't be attributed to direct contact with the enamel. Other researchers such as Stephen et al. [23] made a 3 year clinical trial on fluoride zinc toothpaste at different concentrations. They noticed that $\mathrm{Zn}$ had no influence on dental caries [23]. Lynch et al. [24] performed further studies regarding zinc and fluoride, as a remineralizing agent. They induced artificial carious lesions on bovine teeth and simulated oral conditions, concluding that zinc and fluoride combined showed better remineralization effect compared to fluoride alone [23].

Another remineralizing agent researched was casein phosphopeptide-amorphus calcium phosphate, a milk derived protein [25]. The efficiency of casein is considered unreliable according to studies by Karabekiroglu et al. [25] and Robertson et al. [26] regarding MI Paste Plus (GC America, Alsip, Ill). Beerens et al. [27] and Zhou et al. [28] showed some reduction or improvement in remineralization of white spot lesions (GC Tooth Mousse, Recaldent, GC Corporation). Other authors such as Huang et al. [29] regarding MI Paste Plus (GC America, Alsip, Ill) and Bröchner et al. [30] regarding Tooth Mousse (GC Europe) claimed that major changes regarding microhardness or remineralization after casein use were not observed.

Recently, the use of fluoride with laser irradiation became a specific field of interest to some researchers, such as Fekrazad et al. [31], who studied the acid resistance of the enamel surface around orthodontic brackets after laser irradiation and fluoride application [31]. They concluded that use of an erbium laser with fluoride had produced better results in reducing enamel solubility compared to fluoride alone.

Mahmoudzadeh et al. [32], conducted a study regarding the effect of $\mathrm{CO} 2$ laser and fluoride varnish on enamel surface microhardness. They divided teeth in 5 different groups as follows: a control group, a fluoride varnish group, a $\mathrm{CO} 2$ laser group, a laser before varnish 
group and a laser through varnish group. The conclusion of this study was that enamel microhardness was highest in the fluoride laser group [32]. Another study conducted by Farhadian et al. [33] regarding the use of CPP-ACP paste with or without laser suggested that there was no synergistic remineralizing effect between the two and also CPP-ACP alone or with laser did not produce an increase of the microhardness [33].

Recent studies focused on the effect of the adhesives used for bonding brackets by adding agents such as bioactive glass or metal ions. In a study conducted by Lee et al. [34], they obtained a remineralizing effect by use of a primer with bioactive glass (BAG), BAG and silver or BAG and zinc. The highest microhardness value was obtained by the primer with BAG while the best remineralization potential was achieved by the group with BAG and silver. Another BAG study was conducted by Brown et al. [35] that stated the possibility of remineralization and use of this material for white spot lesion reversal [35]. Oz et al. [36] researched in vivo, adhesives with antibacterial properties and fluoride. Their study did not evidence any differences between the group with the fluoride containing primer and the conventional bonding group. Other interesting new treatment options that were tested for enamel regeneration are the use of strontium doped nano hydroxyapatite molecules. Krishnan et al. [37] developed such a study where hydroxyapatite was synthesized and compared with hydroxyapatite enriched with strontium [37]. It seemed that hydroxyapatite offered a promising result for future enamel repair or regeneration [37].

Brilliant results are published related to a novel treatment offered by a self-assembling peptide p11-4. It seems to achieve visual and microscopic changes on the white spot lesion [38].

Further modalities for treatment of the white spot lesion refer to a camouflage effect by use of resin infiltration. According to Eckstein et al. [39], treatment of white spot lesions depends on dimension, surface depth and microhardness. They conducted a study by utilizing ICON infiltration (DMG, Hamburg, Germany). and observed a decrease in the lesion and durability. Other authors such as Feng et al. [40], Senestraro et al. [41], Knösel et al. [42], Paris et al. [43], Feng et al. [44] seem to agree with the resin infiltration technique because of its aesthetic capacity as it masks the lesion. Ogodescu et al. [45] gained $92.5 \%$ clinical stability with this type of treatment while Kim et al. [46] produced a $61 \%$ masking of post orthodontic decalcification lesions.

Benham et al. suggested using pit and fissure sealants as a masking material for the lesions [47].

Gizani et al. [48] tried the effect of probiotics like Lactobacillus reuteri. According to this research, it seems that daily use of probiotics does not affect nor influence the lesion or its growth [48].

\section{Conclusions}

The use of fluoride as varnish, toothpaste or in various combinations with different agents seems to have an impact in reducing these lesions. CPP-ACP presents pros and cons, therefore further investigations are required in order to establish a firm result. Use of laser and fluoride definitely impacts enamel in a positive manner. Enriching adhesives with different ions seems to have a good influence while use of nanoparticles presented promising results regarding enamel regeneration. There is also the camouflage effect available, which provided excellent aesthetic results.

Although some traditional methods for treating white spot lesions seem to have undesirable results, nowadays with new technologies emerging and with further insight in nanotechnology, eradicating these lesions appears to be achievable in the near future.

\section{References}

1. Chang HS, Walsh LJ, Freer TJ. Enamel demineralization during orthodontic treatment. Aetiology and prevention. Aust Dent J. 1997;42:322-327.

2. Featherstone JD. The continuum of dental caries--evidence for a dynamic disease process. J Dent Res. 2004;83 Spec No C:C39-C42.

3. Chapman JA, Roberts WE, Eckert GJ, Kula KS, GonzálezCabezas C. Risk factors for incidence and severity of white spot lesions during treatment with fixed orthodontic appliances. Am J Orthod Dentofacial Orthop. 2010;138:188-194.

4. Gorelick L, Geiger AM, Gwinnett AJ. Incidence of white spot formation after bonding and banding. Am J Orthod. 1982;81:93-98. 5. Maxfield BJ, Hamdan AM, Tüfekçi E, Shroff B, Best AM, Lindauer SJ. Development of white spot lesions during orthodontic treatment: perceptions of patients, parents, orthodontists, and general dentists. Am J Orthod Dentofacial Orthop. 2012;141:337344.

6. Whitford GM. Acute and chronic fluoride toxicity. J Dent Res. 1992;71:1249-1254.

7. Stafford GL. Fluoride varnish may improve white spot lesions. Evid Based Dent. 2011;12:104-105.

8. Du M, Cheng N, Tai B, Jiang H, Li J, Bian Z. Randomized controlled trial on fluoride varnish application for treatment of white spot lesion after fixed orthodontic treatment. Clin Oral Investig. 2012;16:463-468.

9. Majithia U, Venkataraghavan K, Choudhary P, Trivedi K, Shah $\mathrm{S}$, Virda M. Comparative evaluation of application of different fluoride varnishes on artificial early enamel lesion: An in vitro study. Indian J Dent Res. 2016;27(5):521-527.

10. Restrepo M, Bussaneli DG, Jeremias F, Cordeiro RC, Raveli DB, Magalhães AC, et al. Control of White Spot Lesions with Use of Fluoride Varnish or Chlorhexidine Gel During Orthodontic Treatment A Randomized Clinical Trial. J Clin Pediatr Dent. 2016;40:274-280.

11. He T, Li X, Dong Y, Zhang N, Zhong Y, Yin W, et al. Comparative assessment of fluoride varnish and fluoride film for remineralization of postorthodontic white spot lesions in adolescents and adults over a 6-month period: A single-center, randomized controlled clinical trial. Am J Orthod Dentofacial Orthop. 2016;149:810-819. 
12. Bansal K, Balhara N, Marwaha M. Remineralizing efficacy of Calcarea Fluorica tablets on the artificial carious enamel lesions using scanning electron microscope and surface microhardness testing: in vivo study. Indian J Dent Res. 2014;25:777-782.

13. Baeshen HA, Lingström P, Birkhed D. Effect of fluoridated chewing sticks (Miswaks) on white spot lesions in postorthodontic patients. Am J Orthod Dentofacial Orthop. 2011;140:291-297.

14. Sköld-Larsson K, Sollenius O, Karlsson L, Petersson LG, Twetman S. Effect of fluoridated milk on enamel demineralization adjacent to fixed orthodontic appliances. Acta Odontol Scand. 2013;71:464-468.

15. Gokce G, Savas S, Kucukyilmaz E, Veli I. Effects of toothpastes on white spot lesions around orthodontic brackets using quantitative light-induced fluorescence (QLF): An in vitro study. J Orofac Orthop. 2017;78:480-486.

16. Agarwal A, Pandey H, Pandey L, Choudhary G. Effect of fluoridated toothpaste on white spot lesions in postorthodontic patients. Int J Clin Pediatr Dent. 2013;6(2):85-88.

17. Jo SY, Chong HJ, Lee EH, Chang NY, Chae JM, Cho JH, et al. Effects of various toothpastes on remineralization of white spot lesions. Korean J Orthod. 2014;44:113-118.

18. Ballard RW, Hagan JL, Phaup AN, Sarkar N, Townsend JA, Armbruster PC. Evaluation of 3 commercially available materials for resolution of white spot lesions. Am J Orthod Dentofacial Orthop. 2013;143(4 Suppl):S78-S84.

19. Mensinkai PK, Ccahuana-Vasquez RA, Chedjieu I, Amaechi BT, Mackey AC, Walker TJ, et al. In situ remineralization of white-spot enamel lesions by 500 and 1,100 ppm F dentifrices. Clin Oral Investig. 2012;16:1007-1014.

20. Brudevold F, Steadman LT, Spinelli MA, Amdur BH, Gron P. A study of zinc in human teeth. Arch Oral Biol. 1963;8:135-144. 21. LeGeros RZ, Bleiwas CB, Retino M, Rohanizadeh R, LeGeros JP. Zinc effect on the in vitro formation of calcium phosphates: relevance to clinical inhibition of calculus formation. Am J Dent. 1999; 12:65-71.

22. ten Cate JM. The caries preventive effect of a fluoride dentifrice containing Triclosan and zinc citrate, a compilation of in vitro and in situ studies. Int Dent J. 1993;43(4 Suppl 1):407-413.

23. Stephen KW, Creanor SL, Russell JI, Burchell CK, Huntington E, Downie CF. A 3-year oral health dose-response study of sodium monofluorophosphate dentifrices with and without zinc citrate: anti-caries results. Community Dent Oral Epidemiol. 1988; 16:321-325.

24. Lynch RJ, Churchley D, Butler A, Kearns S, Thomas $\mathrm{GV}$, Badrock TC, et al. Effects of zinc and fluoride on the remineralisation of artificial carious lesions under simulated plaque fluid conditions. Caries Res. 2011;45:313-322.

25. Karabekiroğlu S, Ünlü N, Küçükyilmaz E, Şener S, Botsali MS, Malkoç S. Treatment of post-orthodontic white spot lesions with CPP-ACP paste: A three year follow up study. Dent Mater J. 2017;36:791-797.

26. Robertson MA, Kau CH, English JD, Lee RP, Powers J, Nguyen JT. MI Paste Plus to prevent demineralization in orthodontic patients: a prospective randomized controlled trial. Am J Orthod Dentofacial Orthop. 2011;140:660-668.

27. Beerens MW, van der Veen MH, van Beek H, ten Cate JM. Effects of casein phosphopeptide amorphous calcium fluoride phosphate paste on white spot lesions and dental plaque after orthodontic treatment: a 3-month follow-up. Eur J Oral Sci. 2010;118:610-617.

28. Zhou CH, Sun XH, Zhu XC. Quantification of remineralized effect of casein phosphopeptiode-amorphous calcium phosphate on post-orthodontic white spot lesion. Shanghai Kou Qiang Yi Xue. 2009; 18:449-454.

29. Huang GJ, Roloff-Chiang B, Mills BE, Shalchi S, Spiekerman C, Korpak AM, et al. Effectiveness of MI Paste Plus and PreviDent fluoride varnish for treatment of white spot lesions: a randomized controlled trial. Am J Orthod Dentofacial Orthop. 2013;143:3141.

30. Bröchner A, Christensen C, Kristensen B, Tranæus S, Karlsson L, Sonnesen L, et al. Treatment of post-orthodontic white spot lesions with casein phosphopeptide-stabilised amorphous calcium phosphate. Clin Oral Investig. 2011;15:369-373.

31. Fekrazad R, Ebrahimpour L. Evaluation of acquired acid resistance of enamel surrounding orthodontic brackets irradiated by laser and fluoride application. Lasers Med Sci. 2014;29:17931798.

32. Mahmoudzadeh M, Rezaei-Soufi L, Farhadian N, Jamalian SF, Akbarzadeh M, Momeni M, et al. Effect of CO2 Laser and Fluoride Varnish Application on Microhardness of Enamel Surface Around Orthodontic Brackets. J lasers Med Sci. 2018;9:43-49.

33. Farhadian N, Rezaei-Soufi L, Jamalian SF, Farhadian M, Tamasoki S, Malekshoar M, et al. Effect of CPP-ACP paste with and without $\mathrm{CO} 2$ laser irradiation on demineralized enamel microhardness and bracket shear bond strength. Dental Press J Orthod. 2017;22:53-60.

34. Lee SM, Kim IR, Park BS, Lee DJ, Ko CC, Son WS, et al. Remineralization Property of an Orthodontic Primer Containing a Bioactive Glass with Silver and Zinc. Materials (Basel). 2017;10. pii: E1253.

35. Brown ML, Davis HB, Tufekci E, Crowe JJ, Covell DA, Mitchell JC. Ion release from a novel orthodontic resin bonding agent for the reduction and/or prevention of white spot lesions. An in vitro study. Angle Orthod. 2011;81:1014-1020.

36. Oz AZ, Oz AA, Yazicioglu S. In vivo effect of antibacterial and fluoride-releasing adhesives on enamel demineralization around brackets: A micro-CT study. Angle Orthod. 2017;87(6):841-846. 37. Krishnan V, Bhatia A, Varma H. Development, characterization and comparison of two strontium doped nano hydroxyapatite molecules for enamel repair/regeneration. Dent Mater. 2016;32:646-659.

38. Jablonski-Momeni A, Heinzel-Gutenbrunner M. Efficacy of the self-assembling peptide P11-4 in constructing a remineralization scaffold on artificially-induced enamel lesions on smooth surfaces. J Orofac Orthop. 2014;75:175-190.

39. Eckstein A, Helms HJ, Knösel M. Camouflage effects following resin infiltration of postorthodontic white-spot lesions in vivo: One-year follow-up. Angle Orthod. 2015;85:374-380.

40. Feng C, Liu R, Liu R, Zhao Q, Chu X. Effect of infiltration resin on the color masking of labial enamel white spot lesions. Hua Xi Kou Qiang Yi Xue Za Zhi. 2013;31:597-599.

41. Senestraro SV, Crowe JJ, Wang M, Vo A, Huang G, Ferracane $\mathrm{J}$, et al. Minimally invasive resin infiltration of arrested whitespot lesions: a randomized clinical trial. J Am Dent Assoc. 2013;144:997-1005.

42. Knösel M, Eckstein A, Helms HJ. Durability of esthetic improvement following Icon resin infiltration of multibracketinduced white spot lesions compared with no therapy over 6 months: a single-center, split-mouth, randomized clinical trial. Am J Orthod Dentofacial Orthop. 2013;144:86-96.

43. Paris S, Schwendicke F, Keltsch J, Dörfer C, Meyer-Lueckel $\mathrm{H}$. Masking of white spot lesions by resin infiltration in vitro. $\mathrm{J}$ 


\section{Dental Medicine}

Dent. 2013;41 Suppl 5:e28-e34.

44. Feng CH, Chu XY. Efficacy of one year treatment of icon infiltration resin on post-orthodontic white spots. Beijing Da Xue Xue Bao Yi Xue Ban. 2013;45:40-43.

45. Ogodescu A, Ogodescu E, Talpoş S, Zetu I. Resin infiltration of white spot lesions during the fixed orthodontic appliance therapy. Rev Med Chir Soc Med Nat Iasi. 2011;115:1251-1257.

46. Kim S, Kim EY, Jeong TS, Kim JW. The evaluation of resin infiltration for masking labial enamel white spot lesions. Int $\mathbf{J}$
Paediatr Dent. 2011;21:241-248.

47. Benham AW, Campbell PM, Buschang PH. Effectiveness of pit and fissure sealants in reducing white spot lesions during orthodontic treatment. Angle Orthod. 2009;79:338-345.

48. Gizani S, Petsi G, Twetman S, Caroni C, Makou M, Papagianoulis L. Effect of the probiotic bacterium Lactobacillus reuteri on white spot lesion development in orthodontic patients. Eur J Orthod. 2016;38:85-89. 